\title{
Feasibility of Double-Blind Clinical Trials with Oral Diacetylmorphine: A Randomized Controlled Phase II Study in an Inpatient Setting
}

\author{
Joan Colom Farran ${ }^{a}$ Miguel Casas ${ }^{b, c, h}$ José Pérez de los Cobos ${ }^{c, d}$ \\ Miquel del Río ${ }^{\mathrm{e}}$ Carlos Roncero $^{\mathrm{b}, \mathrm{c}, \mathrm{h}} \quad$ Xavier Castells $^{\mathrm{b}, \mathrm{f}, \mathrm{g}}$ Sergi Valero $^{\mathrm{b}, \mathrm{c}, \mathrm{h}}$ \\ Francisco José Eiroa-Orosab, c, h Francisca Batlle ${ }^{c, d}$ Joan Trujols ${ }^{d, h}$ \\ on behalf of the Catalan Oral Heroin Study Group
}

a Programme on Substance Abuse, Public Health Agency of Catalonia, Government of Catalonia, ${ }^{b}$ Department of Psychiatry, Hospital Universitari Vall d'Hebron, Universitat Autònoma de Barcelona, 'Department of Psychiatry and Forensic Medicine, Universitat Autònoma de Barcelona, dAddictive Behaviours Unit, Department of Psychiatry, Hospital de la Santa Creu i Sant Pau, e Department of Psychiatry, Hospital Universitari Mútua Terrassa, Research Foundation Mútua Terrassa, Universitat de Barcelona, ${ }^{f}$ Unit of Clinical Pharmacology, Department of Medical Sciences, Universitat Autònoma de Barcelona, Barcelona; ${ }^{9}$ Grup de Recerca TransLab, Universitat de Girona, Girona;

hiomedical Research Centers in Mental Health (CIBERSAM), Spain

\section{Key Words}

Immediate-release oral diacetylmorphine - Slow-release oral morphine $\cdot$ Methadone $\cdot$ Double-blind randomized clinical trial $\cdot$ Feasibility studies $\cdot$ Opiate dependence

\footnotetext{
Abstract

The aim of this study was to evaluate the feasibility of conducting double-blind controlled randomized clinical trials using twice-a-day immediate-release oral diacetylmorphine (DAM) in heroin-dependent patients, by means of measuring the capacity of oral DAM to block opiate withdrawal and clinicians' ability to distinguish it from morphine and methadone. This was a randomized, phase II, double-blind, multicenter pilot study comparing immediate-release oral DAM, slow-release oral morphine and oral methadone administered twice a day during 10 days. Forty-five heroin-dependent patients were randomly assigned to these three treatment groups in an inpatient regime. Patients were stabilized with a mean of $350 \mathrm{mg}(\mathrm{SD}=193)$ of immediate-release oral DAM, $108 \mathrm{mg}(\mathrm{SD}=46.2$ ) of slow-release oral morphine and
}

$40 \mathrm{mg}$ ( $\mathrm{SD}=17.9$ ) of methadone. No statistically significant differences were found between any studied medication in clinical outcome. Neither patients nor clinicians were able to identify the administered medication. This study shows the feasibility of double-blind clinical trials using b.i.d. immediate-release oral DAM allowing further phase III clinical trials in the process of introducing oral DAM as a medication for heroin-dependent patients not responding to standard maintenance treatments.

Copyright $\odot 2012$ S. Karger AG, Basel

\section{Introduction}

Heroin dependence is a devastating, chronic psychiatric disorder. The recent increase of opium production has resulted in an increase in heroin use in many nations [1,

Names of members of the Catalan Oral Heroin Study Group are listed in the appendix.

\section{KARGER}

Fax +4161306 1234

E-Mail karger@karger.ch

www.karger.com
(C) 2012 S. Karger AG, Basel

$1022-6877 / 12 / 0186-0279 \$ 38.00 / 0$

Accessible online at:

www.karger.com/ear
Joan Colom Farran

Programme on Substance Abuse

Public Health Agency of Catalonia, Government of Catalonia

C/ Roc Boronat, 81-95, ES-08005 Barcelona (Spain)

E-Mail joan.colom@gencat.cat 
2]. Between 12 and 21 million people are opiate abusers [2]. Heroin is detected in $80 \%$ of acute drug-related deaths in the EU, and almost half of treatment requests for illicit drug use were for heroin dependence [1]. Crude mortality rate and standardized mortality rate among opioiddependent users have been recently found to be, respectively, 2.09 per 100 person-years and 14.66 standardized mortality ratios, particularly during out-of-treatment periods [3].

Agonist maintenance treatment has become a treatment of choice for chronic opioid-dependent patients [4] who cannot achieve abstinence. Methadone maintenance therapy (MMT) has shown to reduce heroin use [5-7], risk of HIV transmission [8], mortality [9] and crime [10, 11]. Further, MMT is associated with global health [12], social functioning improvement [13], increased treatment retention $[7,14]$ and reduction in criminality $[15$, 16]. The use of MMT has been proven to be valid for a wide range of patients even irrespective of psychopathology [17].

However, MMTs have limited effectiveness for some patients $[7,18,19]$ due to a variety of pharmacological, individual and treatment factors. This has led to the development of alternative forms of maintenance treatments. At present, buprenorphine, a partial $\mu$ receptor agonist, although more expensive than methadone [20], has proven its effectiveness [21] and is currently being progressively introduced in both the United States and the EU.

Due to the limitations of methadone and buprenorphine, along with the increases in incidence of infectious diseases associated with heroin use (i.e. HIV, hepatitis B and $\mathrm{C}$, and tuberculosis), various European countries have begun to consider alternative treatments [4], namely oral slow-release morphine [22-24], and parenteral diacetylmorphine (DAM) [25-27].

In the 1990s, Swiss Health Authorities started several clinical trials studying DAM as a maintenance therapy for heroin-addicted patients who did not benefit from existing forms of opioid maintenance therapy [28]. Since then, clinical trials with intravenous or intrapulmonary DAM have been carried out in several countries (Switzerland, Netherlands, UK, Spain, Germany and Canada), showing DAM's effectiveness as an alternative to conventional forms of maintenance treatment [29-34]. Presently, in the UK, Switzerland, Netherlands, Germany and Denmark, DAM can be prescribed as a maintenance therapy in special cases, although a recent publication shows its effectiveness for patients with no previous experience in maintenance treatments [35]. Nevertheless, in many western countries, parenteral DAM is rejected due to a wide range of factors: higher risk of overdose associated with this route of administration, residual 'high' effect in some patients, higher costs of treatment than with MMT, social stigma, etc. Furthermore, because such trials conducted with intravenous DAM were not double blinded, the possibility of biased results cannot be ruled out. Finally, a high rate of adverse events related to the parenteral administration route were found, which can limit the implementation of large-scale DAM maintenance programs [33].

In 1989, the Swiss authorities commissioned an expert report in which oral DAM was described as having clear prolonged opiate effects without the intense and immediate 'high' effect reported with intravenous DAM [36]. As a result of this expert report, oral DAM has been tried in observational studies in Switzerland that showed higher retention compared to historical controls. Furthermore, oral DAM was well tolerated, and the rates of serious adverse events (SAEs) were low [37]. Oral DAM has been shown to provide a suitable pharmacokinetic profile for its clinical use in heroin-dependent patients [38], and clinical trials are being prepared in Andalusia (Spain) and Vancouver (Canada). Since oral DAM does not produce an intense and immediate 'high' effect and has a suitable pharmacokinetic profile, such oral formulation could be considered as an alternative to intravenous or intrapulmonary DAM.

Our group planned to conduct a pivotal clinical trial with oral DAM avoiding the risk related to intravenous or inhalant administration. Before a phase III study in an outpatient setting using objective outcome measures could be conducted, the Health Authorities required the conduction of a randomized, double-blind, phase II clinical trial involving a small number of participants, in order to generate initial data on DAM's ability to decrease opioid withdrawal with a twice a day (b.i.d) schedule and to determine whether patients and staff could identify the administered substance that would prevent effective blinding. This will be done by means of measuring the capacity of oral DAM to block opiate withdrawal and clinicians' ability to distinguish it from morphine and methadone. The present pilot study compared immediate-release oral DAM, slow-release oral morphine and methadone in a b.i.d. regime, in order to study the feasibility of running double-blind clinical trials with oral DAM, allowing future phase III clinical trials, following the standard clinical research procedures for the development of new medications. 
Fig. 1. Flowchart of the study.

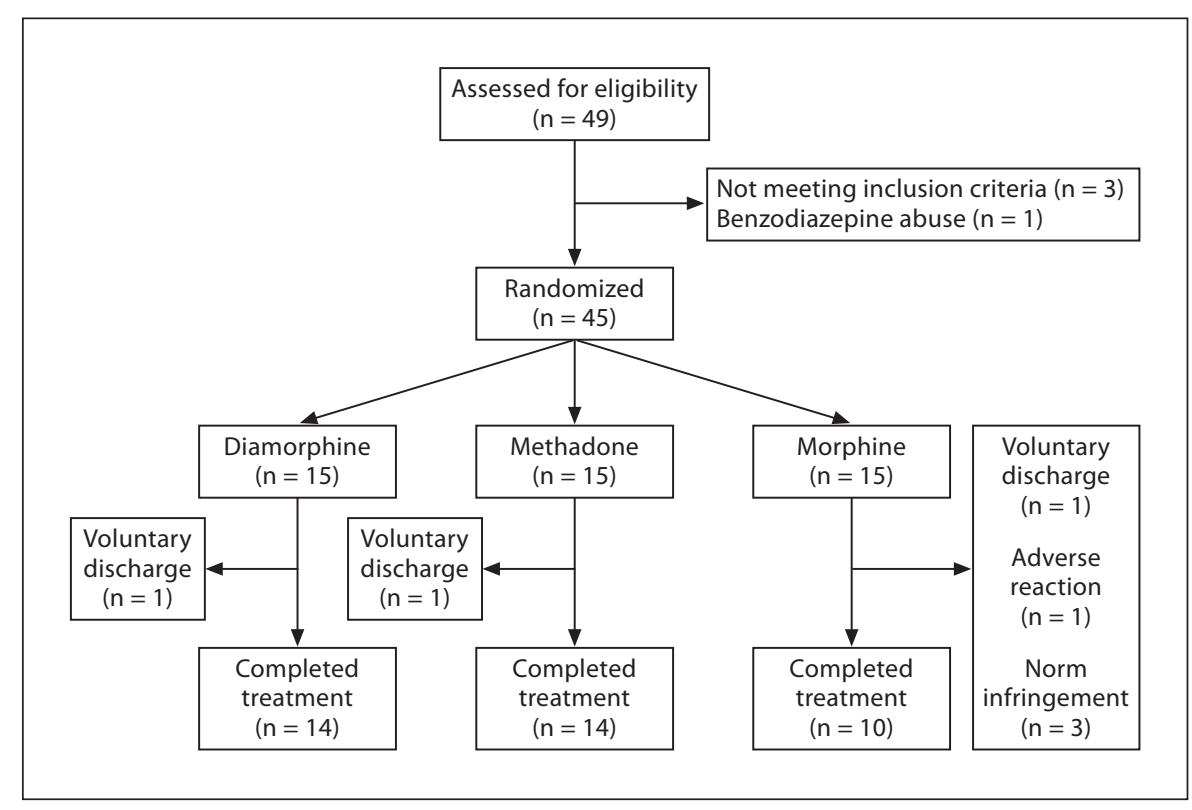

\section{Methods}

\section{Participants}

Forty-five heroin-dependent patients, aged 18-55, were enrolled in this pilot study between 2004 and 2006. Potential participants were selected from individuals not currently receiving treatment but seeking heroin-dependence treatment. Patients were referred from various outpatient substance abuse clinics in Catalonia, Spain. Participants had to meet criteria for heroin dependence according to DSM-IV-TR [39] and have undergone at least one episode of MMT lasting at least one month during which they received a minimum dose of $60 \mathrm{mg}$ per day. Participants also had to test negative for methadone by urinalysis at the screening visit. Subjects were excluded if they were alcohol, cocaine or benzodiazepine dependent, had a major psychiatric or medical disorder, or were receiving treatment with other drugs that could interact with methadone. Women were excluded if they were pregnant, breastfeeding, or were unwilling to use effective contraception methods. Informed consent was obtained from all participants prior to their participation in the study. Participants received no payment for participation. This clinical trial was approved by the internal review boards of the participating hospitals and the Spanish Drug Regulatory Agency, and was conducted in accordance with the Declaration of Helsinki and subsequent amendments.

\section{Design}

A randomized, double-blind, multicenter pilot study was carried out at the Drug Addiction Units of the Departments of Psychiatry of three General Hospitals in Catalonia, Spain. Forty-five participants were randomly assigned to three treatment groups (immediate-release oral DAM, slow-release oral morphine, or methadone), with 15 participants per group (see fig. 1). Participants were admitted to the Drug Addiction Units and received study medication for 10 days. Randomization was performed by a research pharmacist who had no contact with participants or study physicians, using a random numbers table, stratified by center. Thus, each center included 5 patients in each study group. Allocation was concealed by using sequentially numbered, opaque, sealed envelopes.

The main study variables were: (1) mean dose administered to block opioid withdrawal syndrome, (2) presence of subjective and objective opiate withdrawal symptoms, and (3) patient and staff beliefs of which type of opioid was administered. In addition, study retention, heroin craving, symptoms of depression and anxiety, physician and patient's clinical global impression were determined. Opiate withdrawal symptoms were assessed using the Subjective Opiate Withdrawal Scale and the Objective Opiate Withdrawal Scale [40], craving with a $10-\mathrm{cm}$ visual analogue scale [41], global improvement with the Clinical Global Impression Scale [42], depressive symptoms by the Beck Depression Inventory [43], anxiety symptoms by the State-Trait Anxiety Inventory [44], and severity of addiction with the Addiction Severity Index [45]. All variables were assessed daily. Patient and staff beliefs regarding the type of opiate administered were requested on the last day of treatment.

\section{Interventions}

The study was conducted in an in-hospital setting. Study medication consisted of immediate-release oral DAM, slow-release oral morphine and methadone, for which minimum available dosage oral presentations were 50, 15 and $5 \mathrm{mg}$, respectively. Slowrelease oral DAM was not used because when the study was conducted, the pharmacokinetic studies of this sustained release formulation were not available.

Patients were stabilized with an oral b.i.d. flexible dose regime using standard dose increments of 50, 15 and $5 \mathrm{mg}$ of immediaterelease DAM, slow-release morphine and methadone, respectively. All opioids were re-encapsulated with an identical protective coating for each dose (three different colors for each different 
Table 1. Baseline characteristics of randomized patients (mean \pm SD)

\begin{tabular}{|c|c|c|c|}
\hline & $\begin{array}{l}\text { Heroin } \\
(\mathrm{n}=15)\end{array}$ & $\begin{array}{l}\text { Morphine } \\
(\mathrm{n}=15)\end{array}$ & $\begin{array}{l}\text { Methadone } \\
(\mathrm{n}=15)\end{array}$ \\
\hline Males & $100 \%$ & $73.3 \%$ & $80.0 \%$ \\
\hline Age, years & $35.5 \pm 5.0$ & $34.7 \pm 4.2$ & $33.9 \pm 6.4$ \\
\hline At least basic studies completed & $53.3 \%$ & $73.3 \%$ & $73.4 \%$ \\
\hline Unemployed & $60.0 \%$ & $60.0 \%$ & $40.0 \%$ \\
\hline Number of days of heroin consumption during last month & $29.5 \pm 1.5$ & $28.3 \pm 4.8$ & $30 \pm 0.0$ \\
\hline Number of previous maintenance treatments & $1.9 \pm 1.2$ & $1.4 \pm 0.8$ & $1.3 \pm 0.8$ \\
\hline Nicotine dependence & $85.7 \%$ & $78.6 \%$ & $92.3 \%$ \\
\hline Baseline cocaine positive & $60.0 \%$ & $71.4 \%$ & $60.0 \%$ \\
\hline $\mathrm{HIV}$ & $0.0 \%$ & $26.7 \%$ & $20.0 \%$ \\
\hline $\mathrm{HCV}$ & $66.7 \%$ & $80.0 \%$ & $80.0 \%$ \\
\hline \multicolumn{4}{|l|}{ Route of heroin consumption } \\
\hline Intravenous & $71.4 \%$ & $69.2 \%$ & $73.3 \%$ \\
\hline Intrapulmonary & $14.3 \%$ & $30.8 \%$ & $20.0 \%$ \\
\hline Intranasal & $14.3 \%$ & $0.0 \%$ & $6.7 \%$ \\
\hline \multicolumn{4}{|l|}{ Addiction Severity Index composite scores at baseline } \\
\hline Physical state of health & $0.48 \pm 0.33^{*}$ & $0.26 \pm 0.36^{* *}$ & $0.35 \pm 0.29^{*}$ \\
\hline Economic situation & $0.7 \pm 0.37^{*}$ & $0.72 \pm 0.22^{* *}$ & $0.56 \pm 0.24^{*}$ \\
\hline Drug use & $0.38 \pm 0.1^{*}$ & $0.44 \pm 0.14^{* *}$ & $0.42 \pm 0.12^{*}$ \\
\hline Alcohol use & $0.6 \pm 0.1^{*}$ & $0.8 \pm 0.13^{* *}$ & $0.18 \pm 0.17^{*}$ \\
\hline Legal status and problems & $0.39 \pm 0.32^{*}$ & $0.18 \pm 0.15^{* *}$ & $0.22 \pm 0.27^{*}$ \\
\hline Family relationships & $0.49 \pm 0.32^{*}$ & $0.37 \pm 0.14^{* *}$ & $0.47 \pm 0.22 *$ \\
\hline Mental status & $0.31 \pm 0.21^{*}$ & $0.33 \pm 0.21^{* *}$ & $0.39 \pm 0.28^{*}$ \\
\hline
\end{tabular}

No statistically significant differences were found. ${ }^{*} \mathrm{n}=10 ;{ }^{*} \mathrm{n}=5$.

dose). The protocol of drug administration was as follows: During the 1st day, patients were monitored, and each time they showed objective signs of opiate withdrawal as measured by the Opiate Withdrawal Scale, one standard dose was given. The total amount of medication administered during the first day was divided into two equal doses given in a 12-hour interval on the 2 nd day. If the sum of the number of standard doses administered on the 1st day was an odd number, the amount of medication needed could not be divided into two equal doses. In this case, the doses were administered in such a way that the morning dose was higher than the afternoon one while maintaining the same total dosage per day. During this 2nd day, rescue standard doses could be administered if a patient showed objective signs of opiate withdrawal according to the Opiate Withdrawal Scale. The total amount of medication administered (scheduled and rescues) during the 2 nd day was subjected to the same procedure to calculate the doses for the 3 rd day. The same procedure was used during the remaining days of the trial. Once the trial ended, all study medication was stopped, and patients could choose between opioid detoxification and MMT. All participants received no standardized psychosocial management.

\section{Statistical Analysis}

Statistical analysis was performed by intention to treat. The study examined differences within each group of treatment comparing the changes in scores at baseline and at 10 days. The difference between baseline and final values was used to carry out the analysis of treatment efficacy, and Cohen's d of these differences were calculated with $95 \%$ confidence intervals. Last observation carried forward methodology was used for imputing missing values. Sociodemographic data were analyzed using $\chi^{2}$ or mean comparisons according the nature of variables. Analysis of variance (ANOVA) was used to test differences between the three treatment groups on differences between baseline and last moment. Hypotheses were two tailed and 95\% confidence level was used.

\section{Results}

As shown in table 1, the sample was composed of $84.4 \%$ men, and mean age was $34.7(\mathrm{SD}=5.1) .93 .3 \%$ had at least primary studies and $44.7 \%$ were employed. The most common route of heroin use was intravenous (71.4\%), followed by intrapulmonary $(21.4 \%)$ and intranasal (7.1\%). Most patients (71.1\%) had failed previously one MMT episode, and the remaining $28.9 \%$ had failed two or more. Nicotine dependence was present in $85.4 \%$ of the sample, HIV infection in $15.6 \%$ and $\mathrm{HCV}$ infection in $75.6 \%$. No statistically significant differences were found between treatment groups in baseline characteris- 
Table 2. Dose of study medication (mg/day)

\begin{tabular}{llrl}
\hline Day & Heroin & \multicolumn{1}{c}{ Morphine } & Methadone \\
\hline 1 & $133.4 \pm 104.7$ & $54.6 \pm 26.7$ & $21.3 \pm 12.0$ \\
2 & $260.0 \pm 209.8$ & $101.8 \pm 39.5$ & $41.0 \pm 16.4$ \\
3 & $282.2 \pm 161.3$ & $99.2 \pm 32.1$ & $44.7 \pm 17.7$ \\
4 & $310.7 \pm 150.9$ & $120.0 \pm 38.5$ & $45.4 \pm 18.6$ \\
5 & $321.5 \pm 176.2$ & $117.0 \pm 43.5$ & $44.3 \pm 14.9$ \\
6 & $335.7 \pm 161.0$ & $114.0 \pm 43.7$ & $41.8 \pm 15.4$ \\
7 & $346.5 \pm 179.2$ & $115.5 \pm 41.3$ & $42.9 \pm 15.5$ \\
8 & $353.6 \pm 191.6$ & $109.5 \pm 41.3$ & $41.4 \pm 16.3$ \\
9 & $350.0 \pm 193.2$ & $109.5 \pm 45.9$ & $40.4 \pm 17.5$ \\
10 & $350.0 \pm 193.2$ & $108.0 \pm 46.3$ & $40.0 \pm 17.9$ \\
\hline
\end{tabular}

Values are expressed as mean \pm standard deviation.

tics. No statistically significant differences in Addiction Severity Index scores were observed between the study groups at baseline.

Patients were stabilized with a mean of $350 \mathrm{mg}$ (SD = 193) of oral immediate-release heroin, $108 \mathrm{mg}(\mathrm{SD}=46.2)$ of oral slow-release morphine and $40 \mathrm{mg}(\mathrm{SD}=17.9)$ of methadone. Table 2 shows the dose of study medication that was administered every study day. The majority of patients (82.2\%) completed the study. No group effect was found regarding retention in treatment. However, as it was the principal study outcome, it was further explored. Accordingly, in the context of post-hoc comparisons, morphine treatment was found to be statistically lower than heroin and methadone $(\mathrm{z}=2.12, \mathrm{p}=0.034)$. Nevertheless, this effect disappeared after Bonferroni adjustment for multiple comparisons $(0.05 / 3=0.017)$. Treatment improved the scores in all areas (withdrawal symptoms, craving, mood, anxiety and clinical impression) assessed for each group separately from baseline to study end (table 3). Nevertheless, no statistical differences were found in any of these measures between the three different treatment groups.

Blinding was good as proved by the fact that the sum of correct judgments about the administered opioid was $49 \%$ for physicians and $29 \%$ for patients. No statistically significant differences were found between proportions of concordance in the two groups. Neither clinicians nor patients reported a statistically different rate of correct judgments than expected from chance.

Regarding safety, 20 different types of SAEs were reported during the 10-day study period (table 4). Only one adverse event (comitial crisis in a patient with history of seizures) was considered serious, and entailed the with-
Table 3. Efficacy of oral presentations of immediate-release heroin, slow-release morphine and methadone

\begin{tabular}{|c|c|c|c|}
\hline & $\begin{array}{l}\text { Heroin } \\
(n=15)\end{array}$ & $\begin{array}{l}\text { Morphine } \\
(\mathrm{n}=15)\end{array}$ & $\begin{array}{l}\text { Methadone } \\
(\mathrm{n}=15)\end{array}$ \\
\hline Completers & 14 & 10 & 14 \\
\hline Retention, \% & 93.3 & 66.7 & 93.3 \\
\hline Dose, SU & $7 \pm 3.9$ & $7.2 \pm 3.1$ & $8 \pm 3.6$ \\
\hline Dose, $\mathrm{mg}$ & $350 \pm 193$ & $108 \pm 46.2$ & $40 \pm 17.9$ \\
\hline Rescues, SU & $-0.16 \pm 0.29$ & $-0.25 \pm 0.61$ & $0.03 \pm 0.30$ \\
\hline Rescues, mg & $8 \pm 14.5$ & $3.8 \pm 9.15$ & $0.15 \pm 1.50$ \\
\hline \multicolumn{4}{|l|}{ Withdrawal syndrome } \\
\hline Baseline OOWS & $4.07 \pm 2.69$ & $5.14 \pm 3.21$ & $5.47 \pm 3.80$ \\
\hline$\Delta$ OOWS & $-3.1 \pm 2.5$ & $-3.6 \pm 2.9$ & $-4.5 \pm 4.6$ \\
\hline Cohen's d & 1.15 & 1.12 & 1.18 \\
\hline $95 \% \mathrm{CI}$ & $0.38-1.92$ & $0.35-1.89$ & $0.40-1.96$ \\
\hline SOWS basal & $19.00 \pm 11.39$ & $25.14 \pm 12.49$ & $23.13 \pm 14.99$ \\
\hline$\Delta$ SOWS & $-14.8 \pm 13.5$ & $-11.1 \pm 10.5$ & $-19.9 \pm 16.0$ \\
\hline Cohen's d & 1.30 & 0.89 & 1.33 \\
\hline $95 \% \mathrm{CI}$ & $0.51-2.09$ & $0.14-1.64$ & $0.54-2.12$ \\
\hline \multicolumn{4}{|l|}{ Craving (VAS) } \\
\hline Baseline craving & $14 \pm 3.86$ & 5.34 & $5.56 \pm 3.70$ \\
\hline$\Delta$ Craving & $-2.3 \pm 4.6$ & $-3.1 \pm 3.4$ & $-4.8 \pm 4.4$ \\
\hline Cohen's d & 0.60 & 0.79 & 1.30 \\
\hline $95 \% \mathrm{CI}$ & $0-1.33$ & $0.05-1.53$ & $0.51-2.09$ \\
\hline \multicolumn{4}{|l|}{ Depressive symptoms } \\
\hline Baseline BDI & $16.71 \pm 6.06$ & $20.29 \pm$ & $19.47 \pm 12.91$ \\
\hline$\Delta \mathrm{BDI}$ & $-8.43 \pm 6.90$ & $-6.43 \pm 8.34$ & $-9.47 \pm 7.32$ \\
\hline Cohen's d & 1.40 & 0.86 & 0.77 \\
\hline $95 \% \mathrm{CI}$ & $0.60-2.20$ & $0.11-1.61$ & $0.03-1.51$ \\
\hline$\% \Delta \mathrm{BDI} \geq 50 \%$ & 66.7 & 46.7 & 86.7 \\
\hline \multicolumn{4}{|l|}{ Anxiety symptoms } \\
\hline STAI basal & 30.07 & 36. & 34.9 \\
\hline$\Delta$ STAI & $-10.00 \pm 10.38$ & $-12.50 \pm 11.13$ & $-13.57 \pm 7.29$ \\
\hline Cohen's d & 1.09 & 1.63 & 1.46 \\
\hline $95 \% \mathrm{CI}$ & $0.32-1.86$ & $0.80-2.46$ & $0.65-2.27$ \\
\hline$\% \Delta \mathrm{STAI} \geq 30 \%$ & 53.3 & 46.7 & 66.7 \\
\hline $\begin{array}{l}\text { Observer-rated base- } \\
\text { line impression }\end{array}$ & $2.53 \pm 1.06$ & $2.93 \pm 1.33$ & $2.47 \pm 1.06$ \\
\hline$\Delta$ Impression & $-1.00 \pm 1.22$ & $-0.70 \pm 1.16$ & $-1.08 \pm 1.26$ \\
\hline Cohen's d & 0.94 & 0.53 & 1.02 \\
\hline $95 \% \mathrm{CI}$ & $0.19-1.69$ & $0-1.26$ & $0.26-1.78$ \\
\hline $\begin{array}{l}\text { Patient-rated base- } \\
\text { line impression }\end{array}$ & $2.47 \pm 1.25$ & $2.93 \pm 1.33$ & $2.36 \pm 1.15$ \\
\hline$\Delta$ Impression & $-1.54 \pm 1.71$ & $-0.70 \pm 1.16$ & $-1.08 \pm 1.26$ \\
\hline Cohen's d & 1.23 & 0.53 & 1.11 \\
\hline $95 \% \mathrm{CI}$ & $0.45-2.01$ & $0-1.26$ & $0.34-1.88$ \\
\hline
\end{tabular}

No statistically significant differences were found for any analysis. SU = Standard unit; VAS = visual analogue scale; $\Delta=$ difference between basal and final score; OOWS = Objective Opiate Withdrawal Scale; SOWS = Subjective Opiate Withdrawal Scale; BDI = Beck Depression Inventory; STAI = State-Trait Anxiety Inventory. 
Table 4. SAEs reported during the 10-day study period

\begin{tabular}{llll}
\hline & $\begin{array}{l}\text { Heroin } \\
(\mathrm{n}=15)\end{array}$ & $\begin{array}{l}\text { Morphine } \\
(\mathrm{n}=15)\end{array}$ & $\begin{array}{l}\text { Methadone } \\
(\mathrm{n}=15)\end{array}$ \\
\hline $\begin{array}{l}\text { Withdrawal due to SAEs } \\
\text { Reported SAEs }\end{array}$ & 0 & $1(6.7)$ & 0 \\
$\begin{array}{l}\text { Insomnia } \\
\text { Vomits }\end{array}$ & $7(46.7)$ & $9(60)$ & $11(73.3)$ \\
Ototubaritis & 0 & 0 & $2(13.3)$ \\
Arterial hypotension & 0 & $1(6.7)$ & 0 \\
Constipation & 0 & $1(6.7)$ & $1(6.7)$ \\
Cephalea & $4(26.7)$ & $2(13.3)$ & $4(26.7)$ \\
Chalazion & $1(6.7)$ & $1(6.7)$ & 0 \\
Phlebitis & $1(6.7)$ & 0 & 0 \\
Pruritus & 0 & $2(13.3)$ & 0 \\
Dizziness & $2(13.3)$ & $1(6.7)$ & $2(13.3)$ \\
Epigastralgia/dyspepsia & 0 & 0 & $1(6.7)$ \\
Odontalgia & $2(13.3)$ & 0 & $3(20)$ \\
Posttraumatic pain & 0 & 0 & $1(6.7)$ \\
Heart block & 0 & 0 & $2(13.3)$ \\
Backalgia & 0 & 0 & $1(6.7)$ \\
URTI & 0 & 0 & $1(6.7)$ \\
Conjunctivitis & 0 & 0 & $1(6.7)$ \\
Pneumonia & 0 & $1(6.7)$ & 0 \\
Diarrhea & $1(6.7)$ & 0 & 0 \\
Convulsions & 0 & 0 & $1(6.7)$ \\
\hline SAEs & 0 & $1(6.7)$ & 0 \\
\hline & 0 & & \\
\hline
\end{tabular}

SAEs $=$ Serious adverse events; URTI = upper respiratory tract infection. Figures in parentheses indicate percentages.

drawal of the patient from the study. Finally, no significant differences were found in the number of adverse events between study groups.

\section{Discussion}

This first phase II study requested by the Health Authorities constitutes the first randomized clinical trial comparing b.i.d. immediate-release oral DAM, slow-release oral morphine and methadone supporting the feasibility of running double-blind clinical trials with oral DAM in opioid-dependent patients. This is supported by first, the finding that the administration of immediaterelease oral DAM could effectively reduce the opioid withdrawal syndrome, decrease heroin craving and improve depressive and anxiety symptoms similar to slowrelease oral morphine and methadone; second, because neither patients nor clinicians seem to be able to identify which was the administered drug.
The dose needed to block opiate withdrawal with immediate-release oral DAM, slow-release oral morphine and methadone was 350, 108 and $40 \mathrm{mg} /$ day, respectively. The oral DAM to methadone ratio in our study was approximately 9 , which is quite similar to the bioequivalence found in the Swiss heroin-assisted treatment studies $[37,46]$. Regarding morphine stabilization dose, it was expected to be higher because morphine bioavailability appears to be higher with oral DAM than with oral morphine [47]. Other studies have found that the slow-release morphine to methadone ratio was 4.5 [48], while in our study it was of 2.7. It is likely that the slow-release morphine dose in our study was too low, thereby explaining the lower retention in treatment amongst patients randomized to slow-release morphine compared to methadone or DAM. Given this limitation, the bioequivalence between oral methadone and oral DAM must be seen as more convincing than those between methadone and morphine.

It is notable that patients were stabilized with a b.i.d. schedule of the three study medications. This finding, striking for oral DAM, is consistent with that of recent studies showing that heroin-dependent patients are able to be maintained with an average of 2 intrapulmonary or intravenous DAM administrations [30, 33]. It can be explained because, as shown in pharmacokinetic studies $[38,49]$, DAM metabolization yields the production of active metabolites including 6-mono-acetyl-morphine, morphine, and morphine-6-glucoronide with long halflife. The existence of these metabolites could explain why oral and parenteral DAM is able to block opiate withdrawal syndrome with a b.i.d. administration, which is a suitable regime for a maintenance treatment. As slow-release oral DAM is being developed at present [50], it may be possible in a near future to reliably stabilize heroin addicts with a once-a-day regime of slow-release oral DAM.

Patients were stabilized with $40 \mathrm{mg}$ of methadone. It must be noted that patients were admitted to a detoxification unit, and in this setting it is likely that the exposure to cues is lower thereby decreasing craving, anxiety and withdrawal symptoms and the need for methadone. Besides, it must also be stressed that this dose is lower than the one used in methadone maintenance programs for which doses above $60 \mathrm{mg} /$ day are recommended. Higher doses are needed in methadone maintenance programs because their aim is not only to prevent heroin withdrawal but also to cause a narcotic blockade [51]. Given that our study has shown that the equivalent dose to treat the opioid withdrawal syndrome with oral DAM and methadone was 350 and $40 \mathrm{mg} /$ day, respectively, and consider- 
ing that in methadone maintenance programs patients are stabilized with doses ranging between 60 and $125 \mathrm{mg} /$ day, we reckon that the dose of oral DAM needed in maintenance programs will be between 540 and $1,100 \mathrm{mg} /$ day.

This study also shows that oral DAM has a good safety profile. No serious physical complaints were reported, and although high tolerance has been documented for DAM, this study shows that when it is administered under controlled clinical conditions, even in a flexible regime, it has low risk of physical tolerance. Finally, no overdoses were registered. In intravenous DAM studies, overdose was the most hazardous SAE; nevertheless, it mostly occurred in heroin administration clinics and were treated and resolved without sequelae or hospital admission [33].

Some study limitations must be stressed. The sample size was small and, as a consequence, the power of statistical results was also low. In this study, inferential statistics have only an exploratory purpose. However, despite the large confidence intervals observed, also a consequence of the sample size, some size effects obtained comparing basal and final data can be interpreted as large [52]. Under our point of view, it is important to remark that some percentual differences between groups should be perceived as clinically relevant (for example different retention percentages). A placebo arm was not included in order to provide an active treatment to all study participants according to the European regulation. Patients were treated in an inpatient regime in the context of a short follow-up, with reduced exposition to environmental stimulus that may lead to drug craving. This artificial setting was needed to monitor patient safety and warrant double-blind conditions. Another issue that limits the external validity of our study is that we excluded patients with comorbid benzodiazepine, cocaine and alcohol dependence, which are rather prevalent amongst heroin-dependent patients. Besides, our study focused on clinical outcome measures, but we did not fully investigate the behavioral effects of oral DAM or its impact on physiological variables, which should be studied in the future to characterize the clinical pharmacology of this drug. Although administering methadone twice a day limits the external validity of our study, dividing methadone dose is usually recommended in patients that can be very fast methadone metabolizers or in patients for whom once-aday methadone administration cannot prevent heroin craving for $24 \mathrm{~h}[53,54]$. Furthermore, using once-a-day oral DAM was not possible given that, by the time this study was designed and approved, the slow-release for- mulation had not completed the phase I studies [50]. Therefore, a twice-a-day administration of all study medication was needed to allow double-blind conditions. Given that slow-release DAM formulation is available nowadays, caution is recommended when extrapolating our findings to this formulation. The present study was not aimed at investigating oral DAM efficacy with respect to morphine and methadone, or proposing it as a maintenance treatment but at investigating the feasibility of double-blind clinical trials with oral DAM. Our findings suggest that the oral formulation of DAM could be effective and safe, allowing double-blind clinical trials in future research with DAM as a maintenance treatment in outpatient resources.

Further research is warranted using double-blind, randomized clinical trials with oral DAM in the process of introducing oral DAM as a medication in heroin addiction.

\section{Appendix}

The Catalan Oral Heroin Study Group is composed of the following researchers (in alphabetical order): Alvarós Costa J., Arroyo Zamora C., Batlle F., Blasi López A., Bosch Munsó R., Bruguera Cortada E., Casas Brugué M., Castells Cervelló X., Collazos Sánchez F., Colom Farran J., del Río Meyer M., Egido Polo A., Eiroá Orosa F.J., Gonzalvo Cirac B., Majó Roca X., Mir Duñach J., Pérez de los Cobos Peris J.C., Pinet Ogué C., Ramírez Vila M., Ramos Quiroga J.A., Ribalta Corona E., Roncero Alonso C., Sanz Ruíz R., Tascón López Y., Tejero Pociello A., Trujols Albet J., Valero Ventura S.

\section{Acknowledgements}

We would like to thank the patients and staff who participated in the study, as well as the Department of Health of the Government of Catalonia (Generalitat de Catalunya) for funding the study.

\section{Disclosure Statement}

This trial was commissioned and funded by a working group of the Government of Catalonia, Spain. The first author is a member of this institution and had a further role in the study development. The remaining authors have no conflicts of interest. 


\section{References}

1 European Monitoring Centre for Drugs and Drug Addiction: Annual Report 2008: The State of the Drugs Problem in Europe. Luxembourg, Office for Official Publications of the European Communities, 2011.

2 United Nations: Office of Drug and Crime: World Drug Annual Report 2011. Vienna, United Nations Publications, 2011.

-3 Degenhardt L, Bucello C, Mathers B, Briegleb C, Ali H, Hickman M, McLaren J: Mortality among regular or dependent users of heroin and other opioids: a systematic review and meta-analysis of cohort studies. Addiction 2011;106:32-51.

4 Haasen C, van den Brink W: Innovations in agonist maintenance treatment of opioid-dependent patients. Curr Opin Psychiatry 2006;19:631-636.

$>5$ Dole VP: What have we learned from three decades of methadone maintenance treatment? Drug Alcohol Rev 1994;13:3-4.

6 Kreek MJ: Methadone-related opioid agonist pharmacotherapy for heroin addiction: history, recent molecular and neurochemical research and future in mainstream medicine. Ann N Y Acad Sci 2000;909:186-216.

7 Mattick RP, Breen C, Kimber J, Davoli M: Methadone maintenance therapy versus no opioid replacement therapy for opioid dependence. Cochrane Database Syst Rev 2009;CD002209.

-8 Gowing LR, Farrell M, Bornemann R: Brief report: methadone treatment of injecting opioid users for prevention of HIV infection. J Gen Intern Med 2006;21:193-195.

$\checkmark 9$ Brugal MT, Domingo-Salvany A, Puig R, Barrio G, García de Olalla P, de la Fuente L: Evaluating the impact of methadone maintenance programmes on mortality due to overdose and aids in a cohort of heroin users in Spain. Addiction 2005;100:981-989.

10 Marsch LA: The efficacy of methadone maintenance interventions in reducing illicit opiate use, HIV risk behavior and criminality: a meta-analysis. Addiction 1998;93: 515-532.

-11 Werb D, Kerr T, Marsh D, Li K, Montaner J, Wood E: Effect of methadone treatment on incarceration rates among injection drug users. Eur Addict Res 2008;14:143-149.

- 12 Torrens M, San L, Martinez A, Castillo C, Domingo-Salvany A, Alonso J: Use of the Nottingham health profile for measuring health status of patients in methadone maintenance treatment. Addiction 1997;92:707716.

13 Maremmani I, Pani PP, Pacini M, Perugi G: Substance use and quality of life over 12 months among buprenorphine maintenance-treated and methadone maintenancetreated heroin-addicted patients. J Subst Abuse Treat 2007;33:91-98.
14 Farré M, Mas A, Torrens M, Moreno V, Camí $\mathrm{J}$ : Retention rate and illicit opioid use during methadone maintenance interventions: a meta-analysis. Drug Alcohol Depend 2002. 65:283-290.

15 Gossop M (ed): Treating Drug Misuse Problems: Evidence of Effectiveness. London, National Treatment Agency for Substance Misuse, 2006

16 Schwartz RP, Jaffe JH, O’Grady KE, Kinlock TW, Gordon MS, Kelly SM, Wilson ME, Ahmed A: Interim methadone treatment: impact on arrests. Drug Alcohol Depend 2009;103:148-154.

17 Pani PP, Maremmani I, Pacini M, Lamanna F, Maremmani AGI, dell'Osso L: Effect of psychiatric severity on the outcome of methadone maintenance treatment. Eur Addict Res 2011;17:80-89.

18 Mino A, Page D, Dumont P, Broers B: Treatment failure and methadone dose in a public methadone maintenance treatment programme in Geneva. Drug Alcohol Depend 1998;50:233-239.

19 Morral AR, Belding MA, Iguchi MY: Identifying methadone maintenance clients at risk for poor treatment response: Pretreatment and early progress indicators. Drug Alcohol Depend 1999;55:25-33.

20 Jones ES, Moore BA, Sindelar JL, O'Connor PG, Schottenfeld RS, Fiellin DA: Cost analysis of clinic and office-based treatment of opioid dependence: results with methadone and buprenorphine in clinically stable patients. Drug Alcohol Depend 2009;99:132140.

21 Mattick RP, Kimber J, Breen C, Davoli M: Buprenorphine maintenance versus placebo or methadone maintenance for opioid dependence. Cochrane Database Syst Rev 2008;CD002207.

22 Kraigher D, Jagsch R, Gombas W, Ortner R, Eder H, Primorac A, Fischer G: Use of slowrelease oral morphine for the treatment of opioid dependence. Eur Addict Res 2005;11: 145-151.

23 Kastelic A, Dubajic G, Strbad E: Slow-release oral morphine for maintenance treatment of opioid addicts intolerant to methadone or with inadequate withdrawal suppression. Addiction 2008;103:1837-1846.

24 Giacomuzzi S, Kemmler G, Ertl M, Riemer Y: Opioid addicts at admission vs. slow-release oral morphine, methadone, and sublingual buprenorphine maintenance treatment participants. Subst Use Misuse 2006;41:223244.

25 Hartnoll RL, Mitcheson MC, Battersby A, Brown G, Ellis M, Fleming P, Hedley N: Evaluation of heroin maintenance in controlled trial. Arch Gen Psychiatry 1980;37:877-884.

-26 Drucker E: Injectable heroin substitution treatment for opioid dependency. Lancet 2001;358:1385-1385.
27 Lintzeris N: Prescription of heroin for the management of heroin dependence: current status. CNS Drugs 2009;23:463-476.

28 Rehm J, Gschwend P, Steffen T, Gutzwiller F, Dobler-Mikola A, Uchtenhagen A: Feasibility, safety, and efficacy of injectable heroin prescription for refractory opioid addicts: a follow-up study. Lancet 2001;358:1417-1420

29 Perneger TV, Giner F, del Rio M, Mino A: Randomised trial of heroin maintenance programme for addicts who fail in conventional drug treatments. BMJ 1998;317:13-18.

30 van den Brink W, Hendriks VM, Blanken P, Koeter MWJ, van Zwieten BJ, van Ree JM: Medical prescription of heroin to treatment resistant heroin addicts: two randomised controlled trials. BMJ 2003;327:310.

31 March JC, Oviedo-Joekes E, Perea-Milla E, Carrasco F: Controlled trial of prescribed heroin in the treatment of opioid addiction. J Subst Abuse Treat 2006;31:203-211.

-32 Haasen C, Verthein U, Degkwitz P, Berger J, Krausz M, Naber D: Heroin-assisted treatment for opioid dependence: randomised controlled trial. Br J Psychiatry 2007; 191:5562.

33 Oviedo-Joekes E, Brissette S, Marsh DC, Lauzon P, Guh D, Anis A, Schechter MT: Diacetylmorphine versus methadone for the treatment of opioid addiction. N Engl J Med 2009;361:777-786.

34 Strang J, Metrebian N, Lintzeris N, Potts L, Carnwath T, Mayet S, Williams H, Zador D, Evers R, Groshkova T, Charles V, Martin A, Forzisi L: Supervised injectable heroin or injectable methadone versus optimised oral methadone as treatment for chronic heroin addicts in England after persistent failure in orthodox treatment (RIOTT): a randomised trial. Lancet 2010;375:1885-1895.

-35 Haasen C, Verthein U, Eiroa-Orosa FJ, Schäfer I, Reimer J: Is heroin-assisted treatment effective for patients with no previous maintenance treatment? Results from a German randomised controlled trial. Eur Addict Res 2010;16:124-130.

36 Mino A: Scientific Analysis of the Literature on the Controlled Provision of Heroin or Morphine. Berne, Federal Office of Public Health, 1990.

37 Frick U, Rehm J, Kovacic S, Ammann J, Uchtenhagen A: A prospective cohort study on orally administered heroin substitution for severely addicted opioid users. Addiction 2006;101:1631-1639.

38 Girardin F, Rentsch KM, Schwab MA, Maggiorini M, Pauli-Magnus C, Kullak-Ublick GA, Meier PJ, Fattinger K: Pharmacokinetics of high doses of intramuscular and oral heroin in narcotic addicts. Clin Pharmacol Ther 2003;74:341-352. 
39 American Psychiatric Association: Diagnostic and Statistical Manual of Mental Disorders, ed 4, text rev. Washington, American Psychiatric Association, 2000

40 Handelsman L, Cochrane KJ, Aronson MJ, Ness R, Rubinstein KJ, Kanof PD: Two new rating scales for opiate withdrawal. Am J Drug Alcohol Abuse 1987;13:293-308.

41 Freyd M: The graphic rating scale. J Educ Psychol 1923;14:83-102.

42 National Institute of Mental Health: CGI: Clinical global impressions; in Guy W (ed): Manual for the ECDEU Assessment Battery, ed 2 rev. Bethesda, Chevy Chase, 1970, pp 121-126.

-43 Beck A, Ward C, Mendelson M, Mock J, Erbaugh JK: An inventory for measuring depression. Arch Gen Psychiatry 1961;4:561571.

44 Spielberger CD, Gorsuch RL, Lushene RE: Manual for the State-Trait Anxiety Inventory. Palo Alto, Consulting Psychologists Press, 1970.
45 McLellan AT, Kushner H, Metzger D, Peters R, Smith I, Grissom G, Pettinati H, Argeriou M: The fifth edition of the addiction severity index. J Subst Abuse Treat 1992;9:199-213.

46 Frick U, Rehm J, Zullino D, Fernando M, Wiesbeck G, Ammann J, Uchtenhagen A: Longterm follow-up of orally administered diacetylmorphine substitution treatment. Eur Addict Res 2010;16:131-138.

47 Halbsguth U, Rentsch KM, Eich-Hochli D, Diterich I, Fattinger K: Oral diacetylmorphine (heroin) yields greater morphine bioavailability than oral morphine: bioavailability related to dosage and prior opioid exposure. Br J Clin Pharmacol 2008;66: 781-791.

48 Mitchell TB, White JM, Somogyi AA, Bochner F: Comparative pharmacodynamics and pharmacokinetics of methadone and slowrelease oral morphine for maintenance treatment of opioid dependence. Drug Alcohol Depend 2003;72:85-94.

-49 Inturrisi C, Max M, Foley K, Schultz M, Shin S, Houde R: The pharmacokinetics of heroin in patients with chronic pain. N Engl J Med 1984;310:1213-1217.
50 Perger L, Rentsch KM, Kullak-Ublick GA, Verotta D, Fattinger K: Oral heroin in opioid-dependent patients: pharmacokinetic comparison of immediate and extended release tablets. Eur J Pharm Sci 2009;36:421432.

51 Dole VP, Nyswander ME, Kreek MJ: Narcotic blockade. Arch Intern Med 1966;118:304309 .

52 Cohen J (ed): Statistical Power Analysis for the Behavioral Sciences. Hillsdale, Erlbaum, 1988.

53 Crettol S, Deglon J-J, Besson J, CroquetteKrokkar M, Gothuey I, Hammig R, Monnat M, Huttemann $\mathrm{H}$, Baumann P, Eap CB: Methadone enantiomer plasma levels, $\mathrm{cy}$ p2b6, cyp2c19, and cyp2c9 genotypes, and response to treatment. Clin Pharmacol Ther 2005;78:593-604.

-54 Adinoff B: Divided doses for methadone maintenance. Am J Psychiatry 2008; 165: 303-305. 